Highly efficient organic solar Cells based on a robust room-temperature solution-processed copper iodide hole transporter

Kui Zhao, Guy Olivier Ngongang Ndjawa, Lethy Krishnan Jagadamma, Abdulrahman El Labban, Hanlin $\mathrm{Hu}$, Qingxiao Wang, Ruipeng $\mathrm{Li}$, Maged Abdelsamie, Pierre M. Beaujuge, Aram Amassian

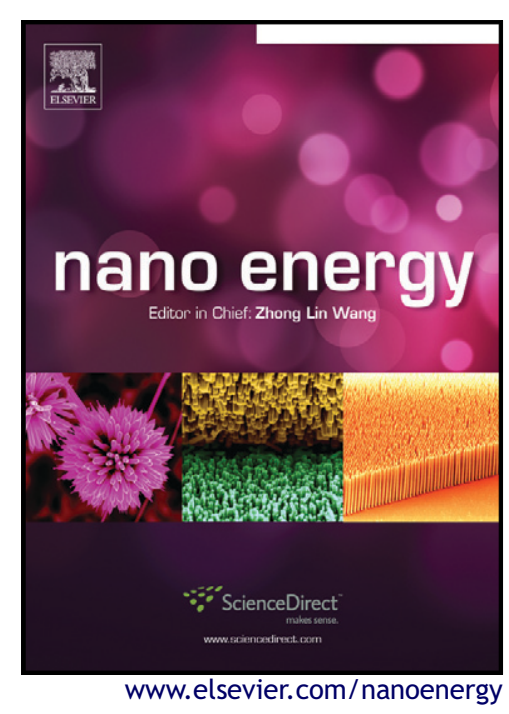

PII: S2211-2855(15)00311-0

DOI: $\quad$ http://dx.doi.org/10.1016/j.nanoen.2015.07.018

Reference: NANOEN919

To appear in: Nano Energy

Received date: 1 April 2015

Revised date: 15 July 2015

Accepted date: 20 July 2015

Cite this article as: Kui Zhao, Guy Olivier Ngongang Ndjawa, Lethy Krishnan Jagadamma, Abdulrahman El Labban, Hanlin Hu, Qingxiao Wang, Ruipeng Li, Maged Abdelsamie, Pierre M. Beaujuge, Aram Amassian, Highly efficient organic solar Cells based on a robust room-temperature solution-processed copper iodide hole transporter, Nano Energy, http://dx.doi.org/10.1016/j.nanoen.2015.07.018

This is a PDF file of an unedited manuscript that has been accepted for publication. As a service to our customers we are providing this early version of the manuscript. The manuscript will undergo copyediting, typesetting, and review of the resulting galley proof before it is published in its final citable form. Please note that during the production process errors may be discovered which could affect the content, and all legal disclaimers that apply to the journal pertain. 


\title{
Highly Efficient Organic Solar Cells Based on a Robust Room- Temperature Solution-Processed Copper Iodide Hole Transporter
}

Kui Zhao, Guy Olivier Ngongang Ndjawa, Lethy Krishnan Jagadamma, Abdulrahman El Labban, Hanlin Hu, Qingxiao Wang, Ruipeng Li, Maged Abdelsamie, Pierre M. Beaujuge, and Aram Amassian*

Materials Science and Engineering, Division of Physical Sciences and Engineering, Solar and Photovoltaic Engineering Research Center, King Abdullah University of Science and Technology (KAUST), Thuwal, Saudi Arabia

*Email: $\underline{\text { aram.amassian@kaust.edu.sa }}$

Keywords: Organic photovoltaics; organic solar cells; copper iodide; hole transporting layer; buffer layer; solution processed

\begin{abstract}
Achieving high performance and reliable organic solar cells hinges on the development of stable and energetically suitable hole transporting buffer layers in tune with the electrode and photoactive materials of the solar cell stack. Here we have identified solution-processed copper(I) iodide $(\mathrm{CuI})$ thin films with low-temperature processing conditions as an effective hole-transporting layer (HTL) for a wide range of polymer:fullerene bulk heterojunction (BHJ) systems. The solar cells using CuI HTL show higher power conversion efficiency (PCE) in standard device structure for polymer blends, up to PCE of $8.8 \%$, as compared with poly $(3,4-$ ethylenedioxy-thiophene):poly(styrenesulfonate) (PEDOT:PSS) HTL, for a broad range of polymer:fullerene systems. The CuI layer properties and solar cell device behavior are shown
\end{abstract}


to be remarkably robust and insensitive to a wide range of processing conditions of the HTL, including processing solvent, annealing temperature (room temperature up to $200^{\circ} \mathrm{C}$ ), and film thickness. $\mathrm{CuI}$ is also shown to improve the overall lifetime of solar cells in the standard architecture as compared to PEDOT:PSS. We further demonstrate promising solar cell performance when using $\mathrm{CuI}$ as top HTL in an inverted device architecture. The observation of uncommon properties, such as photoconductivity of $\mathrm{CuI}$ and templating effects on the $\mathrm{BHJ}$ layer formation, are also discussed. This study points to $\mathrm{CuI}$ as being a good candidate to replace PEDOT:PSS in solution-processed solar cells thanks to the facile implementation and demonstrated robustness of $\mathrm{CuI}$ thin films.

\section{Introduction}

Organic photovoltaics (OPV) have attracted tremendous attention in recent years because of the potential for manufacturing solution-processable, large area devices using potentially low cost, non-toxic materials and manufacturing methods which have a reduced carbon footprint. ${ }^{[1]}$ Efficient OPV devices require hole and electron transporting and buffer layers which prevent recombination of charges at the anode and cathode. ${ }^{[2,3]}$ In the standard OPV device architecture, a transparent anode is traditionally coated with poly(3,4-ethylene dioxythiophene):(polystyrene sulfonic acid) (PEDOT:PSS), so far the most widely used holetransporting layer (HTL) in OPVs. ${ }^{[4]}$ However, the acidic and hygroscopic characteristics of PEDOT:PSS can cause indium loss from the indium tin oxide (ITO) transparent anode, adversely affecting the device stability. ${ }^{[5,6]}$ Recently a few transition metal oxides (TMOs) have been reported as candidate replacements to PEDOT:PSS owing to the energy level compatibility with ITO and to the semiconducting nature of the oxides. This includes materials 
such as nickel oxide $\left(\mathrm{NiO}_{\mathrm{x}}\right),{ }^{7]}$ molybdenum oxide $\left(\mathrm{MoO}_{3}\right),{ }^{[8]}$ tungsten oxide $\left(\mathrm{WO}_{3}\right),{ }^{[9]}$ and vanadium oxide $\left(\mathrm{V}_{2} \mathrm{O}_{5}\right){ }^{[10]}$

An important requirement for such TMO materials is their compatibility with solutionprocessing to enable large-area and high-thoughput production of OPV devices. While most hole transporting oxides are typically vacuum deposited, some of them have been successfully shown to be solution processable, including $\mathrm{NiO}_{\mathrm{x}},{ }^{[11]} \mathrm{MoO}_{3}{ }^{[12]}$ and $\mathrm{V}_{2} \mathrm{O}_{5}{ }^{[13]}$ However, research is still directed toward identifying low temperature means of producing such oxides, as many of them require process temperatures incompatible with roll-to-roll fabrication of OPV devices on plastic substrates. The oxide thin film synthesis methods can also be complex when compared with PEDOT:PSS thin film deposition and can yield highly variable properties depending upon the processing conditions and environments. ${ }^{[14-17]}$

In this manuscript, we report a room-temperature solution-processed inorganic pseudohalide HTL that is simple-to-process and produces high performance OPV devices over a broad range of preparation conditions. Copper(I) iodide $(\mathrm{CuI})$ is inexpensive, abundant, and non-toxic. It is stable enough to be successfully vacuum-deposited as HTL, ${ }^{[18,19]}$ yet can be easily solution-processed at room temperature. ${ }^{[20,21]} \mathrm{CuI}$ was successfully introduced in the past into dye-sensitzed solar cells (DSSCs) by Tennakone and coworkers, ${ }^{[22]}$ in which p-type CuI was used as hole conducting layer. ${ }^{[21-27]}$ Vacuum-deposited $\mathrm{CuI}$ has also been used to template the stacking orientation of vacuum-deposited small-molecule thin films such as zinc phthalocyanine $(\mathrm{ZnPc})^{[28,29]}$ and copper phthalocyanine $(\mathrm{CuPc}){ }^{[30]}$ as well as polymers such as poly(3-hexylthiophene) (P3HT) ${ }^{[31,32]}$ and poly(4-(2-thiophenaniline)) (P42TA) in OPV applications. ${ }^{[33]}$ Here, we characterize in detail solution-processed $\mathrm{CuI}$ thin films in terms of their microstructure, optical and electronic properties. We then successfully apply $\mathrm{CuI}$ as HTL to get power conversion efficiency (PCE) of up to $4.0 \%$ with $\mathrm{P} 3 \mathrm{HT}: \mathrm{PC}_{60} \mathrm{BM}, 6.8 \%$ with 
PBDTTPD:PC $70 \mathrm{BM}, 8.0 \%$ with PTB7:PC $70 \mathrm{BM}$, and $8.8 \%$ with PTB7-Th:PC $70 \mathrm{BM}$ in the standard device architecture, exceeding the performance achieved by PEDOT:PSS with the same material systems. CuI is also shown to work as top HTL in inverted architecture OPV devices. This study highlights the reemergence of pseudohalides, such as $\mathrm{CuI}$ and copper(I) thiocyanate $(\mathrm{CuSCN}),{ }^{[34-36]}$ as an interesting and promissing class of highly transparent materials for use in solution-processed emerging electronic and photovoltaic applications.

\section{Results and discussion}

\subsection{Microstructure and morphology of $\mathrm{CuI}$ thin films}

The CuI solution was prepared by dissolving the $\mathrm{CuI}$ powder into dipropyl sulfide (DPS) or acetonitrile (ACN) and stirring overnight at room temperature. Thin films of CuI were deposited onto cleaned ITO substrates via spin coating of the room temperature solution (see Methods). Scanning electron micrographs (Figure 1a) on CuI film reveal a grainy structure with typical lateral feature size on the order of several hundred nanometers. ${ }^{[21]}$ Atomic force micrographs reveal CuI (inset of Figure 1a) to be rougher $(\sim 3.3 \mathrm{~nm})$ than PEDOT:PSS $(\sim 1.1$ nm) (Figure S1a,b). High resolution transmission electron micrographs (HRTEM) (Figure 1b) obtained in plan-view mode on CuI films solution-cast on a copper grid reveal clear lattice fringes. The fast Fourier transform (FFT) spectral image taken for the selected area indicates the presence of d-spacings of $0.35 \mathrm{~nm}$ and $0.23 \mathrm{~nm}$ which correspond to the (111) and (220) crystalline planes of the $\gamma$-phase of $\mathrm{CuI}$, respectively, which is also confirmed by grazing incidence X-ray diffraction (GIXRD) (Figure 1c) measurements. ${ }^{[37]}$ The plan-view TEM images looking through the polycrystalline $\mathrm{CuI}$ to the $\mathrm{BHJ}$ layer reveal $\mathrm{CuI}$ film retains good uniformity, coverage and crystalline structure after deposition of active layer (Figure S1c-f). The dark-field cross-sectional TEM image (Figures 1d,e) shows the CuI film is sandwiched 
between the ITO and the BHJ layer and forms an abrupt interface with the latter; the FFT analysis shown in the inset of Figure 1e reveals the $\gamma$-phase is maintained after device fabrication. A x-ray photoelectron spectroscopy (XPS) survey scan of the surface of solutionprocessed CuI thin films is shown in (Figure 1f). Analysis of high resolution spectra peaks associated with $\mathrm{Cu}$ and $\mathrm{I}$ is shown in Figure $\mathrm{S} 2$ and summarized in Table 1, confirming a stoichiometric $\mathrm{CuI}$ film prior to $\mathrm{BHJ}$ deposition.

\subsection{Optical and electronic properties of solution-processed $\mathrm{CuI}$ thin films}

In Figure 2a, we plot the optical transmission and absorption spectra of the solutionprocessed $\mathrm{CuI}$ film $(\sim 12 \mathrm{~nm})$ deposited directly on a glass substrate. The transmission of a PEDOT:PSS layer $(\sim 22 \mathrm{~nm})$ spin-cast on glass is also shown for comparison. The average transmittance of the film is about $91 \%$ in the wavelength region above $500 \mathrm{~nm}$ and slightly lower at shorter wavelength, $(89 \%$ at $\lambda=420 \mathrm{~nm})$, until the onset of significant absorption at $\sim 410 \mathrm{~nm}$ and below. While the absorption is higher for CuI than PEDOT:PSS in the ultraviolet, $\mathrm{CuI}$ is more transparent than PEDOT:PSS in the wavelength region above $600 \mathrm{~nm}$. The absorption coefficient is be determined from the transmittance by using the following equation:

$$
\alpha=\frac{1}{t} \ln \left(\frac{1}{T}\right)
$$

where $t$ is the thin film thickness $(\sim 12 \mathrm{~nm})$ and $T$ is the transmittance spectra of the thin films. The direct band gap can be extracted by plotting $(\alpha h v)^{2}$ versus photon energy and extrapolating to intersect with the abscissa (Figure S3). The optical band gap was found to be $2.96 \mathrm{eV}$ which is lower than what was previously reported $(3.1 \mathrm{eV}) .{ }^{[38]}$ The work function (WF) of solutionprocessed $\mathrm{CuI}$ film is determined from ultraviolet photoelectron spectroscopy (UPS) measurements to be $-4.7 \mathrm{eV}$ (Figure $2 \mathbf{b}$ ), shallower than the vacuum-deposited film $(-5.4 \mathrm{eV})$, but still expected to exhibit hole extraction characteristics. The valence band edge of the 
solution-processed $\mathrm{CuI}$ film was determined to be $-4.9 \mathrm{eV}$, which lies significantly higher than for vacuum-deposited $\mathrm{CuI}(\sim 11 \mathrm{~nm},-5.7 \mathrm{eV})$. The reason for this energetic difference is not well understood. However, we have been successful at inducing a significant shift of the energetics in vacuum-deposited CuI films by exposing them to chlorobenzene (Figure S4). The work function decreases to $-5.0 \mathrm{eV}$ and the valence band edge decreases to $-5.3 \mathrm{eV}$. This indicates the solvent interactions may be partially responsible for the energetic shift.

\subsection{Standard P3HT:PC 60 BM solar cells with $\mathrm{CuI}$ as $\mathrm{HTL}$}

The organic solar cell architecture we have explored herein is the standard configuration with HTL at the bottom, as illustrated in Figure 3a. ITO-coated glass substrates were used as the transparent anode, CuI or PEDOT:PSS were used as HTL, Ca and Al were vacuumevaporated as electron transporting layer and top reflective cathode, respectively. We found that the CuI solar cell exhibits higher short circuit current $\left(J_{s c}\right)$ than the PEDOT:PSS device in P3HT:PC ${ }_{60} \mathrm{BM}$ solar cells in a previous report, ${ }^{[32]}$ but this effect was not explained. We believe such effects may stem from testing solar cells without using an aperture in the presence of a reasonably conducting buffer layer and as such may be suspect. In the case of CuI, the asprepared films did exhibit sufficient conductivity to warrant special precautions. We have also observed a significant photo-induced enhancement of the conductivity under light exposure (Figure S5a). The conductivity shows a rapid increase within a few seconds under AM 1.5G solar irradiation at $100 \mathrm{~mW} \mathrm{~cm}$, while no change is measured in PEDOT:PSS films under similar conditions. This effect is not understood, but may be related to the ionic nature of $\mathrm{CuI}$. Measurement artefacts can be introduced by the elevated conductivity of the HTL during $J-V$ measurements and are suspected in prior CuI-related literature. ${ }^{32}$ Such artefacts can be eliminated by using an aperture during solar cell testing (Figure S5b,c). 
In Figure 3b, we plot the J-V characteristics of typical P3HT:PC ${ }_{60} \mathrm{BM}$ BHJ solar cells fabricated on solution-processed and vacuum-deposited CuI. The device parameters, averaged over 5 individual devices, are summarized in Table 2. We have found that the average PCE for these devices is $3.95 \%$ and $3.85 \%$, respectively, with comparatively lower PCE in the case of PEDOT:PSS-based devices (PCE 3.65\%). The improved performance compared to PEDOT:PSS is mainly due to higher fill factor. The external quantum efficiency (EQE) spectra of devices based on solution-processed CuI and PEDOT:PSS are plotted in Figure 3c. They reveal nearly identical EQE with a slightly higher intensity in the 500-600 nm range. However, the UV-Vis absorption spectra of the $\mathrm{P} 3 \mathrm{HT}: \mathrm{PC}_{60} \mathrm{BM} \mathrm{BHJ}$ layer grown on $\mathrm{CuI}$ and PEDOT:PSS look the same (Figure S6), suggesting better photocurrent extraction in the former case.

A key feature of the CuI buffer layer is its robustness and resilience. To highlight this we investigate the sensitivity of solar cell performance metrics to changes in HTL preparation conditions, including thickness (Figure 3d), post-processing temperature (Figure 3e) and choice of processing solvent (Figure 3f) ${ }^{[39]}$ The device parameters are summarized in Table 3 and show very little if any meaningful changes as CuI film thickness was varied from ca. 7 to $20 \mathrm{~nm}$, was annealed in inert atmosphere to $200{ }^{\circ} \mathrm{C}$ or processed using ACN instead of DPS with or without annealing. The only deterioration in device performance is observed when annealing $\mathrm{CuI}$ to $250{ }^{\circ} \mathrm{C}$, resulting in a PCE of $2.96 \%$. Otherwise, all devices exhibited comparable $J_{s c}, V_{o c}, F F$ and PCE. The performance of CuI-based DSSCs has been previously shown to be strongly affected by solution-processing conditions of CuI, which causes the contact between $\mathrm{TiO}_{2}$ and $\mathrm{CuI}$ crystallites to be degraded. ${ }^{[20,21]}$ In contrast to these observations in the context of DSSCs, our results highlight the remarkable reliability and robustness of solution-processed CuI HTLs in response to changes in thickness and processing conditions, 
making it a potentially attractive material for manufacturing of organic and other emerging photovoltaic devices.

The lower band gap of CuI as compared with PEDOT:PSS means that CuI can block part of the ultraviolet radiation responsible for the degradation of OPV devices. This effect is well-known in the context of inverted solar cell devices, where the use of a ZnO ETL on ITO blocks UV radiation from reaching the photoactive layer of OPV devices. ${ }^{[40]}$ In standard devices, use of lower bandgap oxide-based HTL, such as MoOx, has also shown a similar advantage over PEDOT:PSS. ${ }^{[12,41]}$ We have made a simple comparison of the lifetime of nonencapsulated P3HT:PC ${ }_{60} \mathrm{BM}$ solar cells based on PEDOT:PSS and CuI HTLs after being kept in $\mathrm{N}_{2}$ environment. Device parameters including $V_{o c}, J_{s c}, F F$ and PCE are monitored over a 90 days period and are summarized in Figure S7. The results indicate a comparatively slower decline of device performance in case of CuI versus PEDOT:PSS HTL. The $V_{o c}$ and $F F$ remain remarkably stable in both cases, but it is the $J_{s c}$ that suffers the most, with CuI-based devices maintaining their original photocurrent much longer than the PEDOT:PSS-based device. After 90 days, the CuI-based device still shows a PCE $>1 \%$ whereas the PEDOT:PSS device shows no photovoltaic response. The comparison suggests the CuI HTL provides more $J_{s c}$ satiability than does PEDOT:PSS in the standard OPV architecture.

\subsection{Highly efficient polymer:fullerene solar cells based on CuI as HTL}

Based on the success of $\mathrm{CuI}$ as $\mathrm{HTL}$ in $\mathrm{P} 3 \mathrm{HT}: \mathrm{PC}_{60} \mathrm{BM}$ solar cell, it is expected that it may work well for more modern and high performing polymer:fullerene blends, a topic not yet investigated for this material. It is helpful to show the energy levels of the various materials potentially involved in making such solar cells in the standard architecture. We have plotted in Figure 4a the energy levels for a standard OPV device architecture schematically represented 
in Figure 3a. The various active layer material combinations tested, including the donor polymers PBDTTPD, PTB7 and PTB7-Th (also known as PCE-10) as well as the fullerene derivative $\mathrm{PC}_{70} \mathrm{BM}$ are identified in Figure $4 \mathbf{b}$. In Figures 5, we plot the $J-V$ characteristics of OPV devices based on PBDTTPD:PC ${ }_{70} \mathrm{BM}, \mathrm{PTB} 7: \mathrm{PC}_{70} \mathrm{BM}$ and PTB7-Th:PC ${ }_{70} \mathrm{BM}$, respectively, comparing solution-processed CuI and PEDOT:PSS as HTL. It is evident in both cases shown that the solution-processed CuI HTL outperforms PEDOT;PSS. Specifically, best performing CuI-based devices using PTB7:PC ${ }_{70} \mathrm{BM}$ and PTB7-Th:PC ${ }_{70} \mathrm{BM}$ yield PCE of 8.0\% and $8.8 \%$, respectively, substantially better than the best PEDOT:PSS-based cells, which were $7.5 \%$ and $8.4 \%$, respectively. These results continue to support our previous assertions about the excellent quality of $\mathrm{CuI}$ as $\mathrm{HTL}$ in organic solar cells. While the EQE of $\mathrm{P} 3 \mathrm{HT}: \mathrm{PC}_{60} \mathrm{BM}$ devices showed an advantage for CuI-based devices between 500 and $600 \mathrm{~nm}$, the EQE spectra of PTB7:PC 70 BM and PTB7-Th:PC ${ }_{70} \mathrm{BM}$ devices, shown in Figures 5d,f, respectively, reveal higher $\mathrm{EQE}$ in the lower wavelength region between $420 \mathrm{~nm}$ and $550 \mathrm{~nm}$, where $\mathrm{CuI}$ is more absorbing than PEDOT:PSS. The absorption spectra of these blends shown in Figures S8 reveal a higher absorption intensity in the short wavelength between $420 \mathrm{~nm}$ and $550 \mathrm{~nm}$ for both $\mathrm{PTB} 7: \mathrm{PC}_{70} \mathrm{BM}$ and $\mathrm{PTB} 7-\mathrm{Th}: \mathrm{PC}_{70} \mathrm{BM}$, indicating that higher light absorption by the $\mathrm{BHJ}$ layer might be the origin of the EQE differences. We speculate here that the Cul's demonstrated ability to impact molecular packing and orientation, especially at the CuI-BHJ interface may be operant in these solar cells. We investigate this possibility for the P3HT:PC ${ }_{60} \mathrm{BM} \mathrm{BHJ}$ layer system in the next section.

As CuI can be solution-processed from DPS and ACN, there is an opportunity to fabricate inverted organic solar cells with CuI on top of the BHJ layer as top HTL. We have fabricated inverted solar cells with the following device configuration: glass/ITO/ZnO/PTB7:PC ${ }_{70} \mathrm{BM} / \mathrm{CuI} / \mathrm{Ag}$, as shown in Figure 6. The $\mathrm{ZnO}$ layer was prepared 
based on a sol-gel process previously demonstrated ${ }^{[42]}$ CuI HTL was simply prepared by spincoating the dipropyl sulfide solution with a concentration of $100 \mathrm{mg} / \mathrm{mL}$ and diluted by isopropanol solvent ( 20-50 times) without further thermal annealing or any other postdeposition treatment. The isopropanol solvent was added in order to improve the wetting on the BHJ surface. The device shows a promising performance for a first try, with $J_{s c}$ of 13.7 $\mathrm{mA} / \mathrm{cm}^{2}, V_{o c}$ of $0.67 \mathrm{~V}, F F$ of $54.8 \%$ and PCE of $5.1 \%$. Nevertheless, the inverted solar cells exhibit lower efficiency than inverted solar cells made using the same $\mathrm{ZnO}$ ETL and $\mathrm{MoO}_{\mathrm{x}}$ as HTL, which we had shown yields PCE $=6.5 \% .{ }^{[35]}$ We believe that further optimization of the $\mathrm{CuI}$ film processing should yield future improvements, making CuI an interesting HTL for both standard and inverted architecture OPV devices.

\subsection{Discussion of the templating effect of $\mathrm{CuI}$ on the solution-processed BHJ layer}

In light of the previously reported ability of vacuum-deposited $\mathrm{CuI}$ to modulate and template the molecular conformation and crystalline texture of semicrystalline polymers P3HT and $\mathrm{P}_{2} \mathrm{TA}^{[31,33]}$ as well as small-molecule organic semiconductors $\mathrm{ZnPc}$ and $\mathrm{CuPc},{ }^{[28-30]}$ we investigate in this section whether $\mathrm{CuI}$ can influence the molecular orientation and phase separation of the solution-processed bulk heterojunction layers presented herein by focusing mainly on changes to the structural and optical properties of the semi-crystalline P3HT phase in P3HT:PCBM blends. As a first control experiment, we have vacuum-deposited ZnPc thin films on top of the solution-processed PEDOT:PSS and CuI interlayers and confirm through XRD measurements (Figure S9a) that ZnPc takes an edge-on orientation ZnPc on PEDOT:PSS, but not on solution-processed CuI, in agreement with previous studies showing a more face-on packing character on $\mathrm{CuI} .{ }^{[28,29]}$ This indicates that solution-processed $\mathrm{CuI}$ retains the same ability to template self-assembly of small molecule organic semiconductors as do the vacuum- 
deposited CuI films. In case of polymer blends, however we do not expect a significant effect of the templating layer for two main reasons: (1) unlike vacuum deposition, which is initiated at the surface of the substrate, BHJ formation is unlikely to be initiated at the solid-liquid interface and is known to occur with sub-second kinetics, ${ }^{[43]}$ (2) polymer building blocks are much less mobile and ordered than small-molecules and are unlikely to comply with the substrate for an extended length or thickness. Grazing incidence wide-angle X-ray diffraction (GIWAXS) experiments performed on P3HT:PCBM blends spin-cast on ITO, ITO/PEDOT:PSS and ITO/CuI reveal a reduced intensity and more mosaicity of the out-ofplane (100) lamellar Bragg sheet as compared to films spin-cast on PEDOT:PSS (Figures S9b,c and inset of S9c). We have further investigated the anisotropy of chain-packing of P3HT within the BHJ by performing variable angle spectroscopic ellipsometry (VASE) measurements. ${ }^{[43]}$ In the spectral region associated to $\pi-\pi^{*}$ interactions, the model fit, based on a uniaxial anisotropic assumption, reveals reduced ordinary extinction $\left(k_{0}\right.$, in-plane electric field vector) and increasing extraordinary extinction ( $k_{\mathrm{e}}$, out-of-plane) (Figure S8d) when CuI is used instead of PEDOT:PSS, indicating more face-on $\pi$-stacking interactions in the presence of CuI. This is consistent with a more face-on arrangement of P3HT domains observed on vacuum-deposited CuI, as reported by Shao et al. ${ }^{[31]}$ Despite the differences in packing, the performance boost is quite small, perhaps reinforcing the fact that polymer conformation with a BHJ layer is not as critical as in the case of vacuum-deposited small-molecule OPV systems; the role of the HTL is certainly more dramatic in the latter, where molecules adsorb and selfassemble from the $\mathrm{CuI}$ substrate over a period of minutes, whereas the bulk heterojunction forms from a solution of entangled high $\mathrm{Mw}$ polymer chains on the subsecond to second timescale. ${ }^{[4,45]}$ The apparent effect of CuI on the molecular orientation in P3HT domains raises the possibility as well of its effect on the vertical phase separation of the blend components. 
From the cross-sectional EFTEM analysis on P3HT:PC ${ }_{60} \mathrm{BM}$ blends deposited on solutionprocessed CuI and on PEDOT:PSS (Figure S9), a different vertical phase separation of the components, wherein $\mathrm{PC}_{60} \mathrm{BM}$ seems to be more uniformly distributed and possibly present more in the middle of the blend film on PEDOT:PSS and has a tendency to accumulate near the substrate when $\mathrm{CuI}$ is used. The CuI-induced vertical phase separation implies a unique interaction between donor:acceptor components and $\mathrm{CuI}$ film, which might partially be due to much lower surface energy of hydrophobic $\mathrm{CuI}\left(26 \mathrm{~mJ} / \mathrm{m}^{2}\right)$ as compared with hydrophilic PEDOT:PSS $\left(73 \mathrm{~mJ} / \mathrm{m}^{2}\right)$ HTL. ${ }^{[46,47]}$ The apparent reduction of lamellar texture should therefore not necessarily be interpreted as resulting from a preferred face-on orientation of P3HT on CuI, but perhaps more due to the fact that P3HT crystalline domains are predominantly in the bulk and near the surface of the BHJ, and are therefore more randomly oriented than if they were to grow on the flat surface of the substrate. More detailed investigations and further exploration are needed to unravel the possible templating effects that can be used to control molecular orientation within solution-processed BHJ layers. It is clear from this study that CuI leads to noticeable improvements in the performance of OPV devices, but this benefit is not easy to link to changes in the molecular orientation or phase separation.

\section{Conclusions}

We have demonstrated the general utility and effectiveness of a low-temperature solution-processed $\mathrm{CuI}$ film as hole transporting layer in highly efficient polymer:fullerene BHJ solar cells. The standard architecture solar cells with CuI HTL show enhanced PCE across the board when used as a replacement to PEDOT:PSS for P3HT:PC ${ }_{60} \mathrm{BM}$, PBDTTPD: PC 70 BM, PTB7:PC ${ }_{70} \mathrm{BM}$ and PTB7-Th:PC ${ }_{70} \mathrm{BM}$ systems, with $\mathrm{PCE}$ as high as $4.0 \%, 6.8 \%, 8.0 \%$ and $8.8 \%$, respectively, in the standard OPV architecture. The CuI HTL was found to be very 
versatile and robust to improve the stability of standard architecture devices as compared with PEDOT:PSS-based cells. We also show evidence to suggest that $\mathrm{CuI}$ can alter the overall molecular orientation and vertical phase separation within $\mathrm{P} 3 \mathrm{HT}: \mathrm{PC}_{60} \mathrm{BM} \mathrm{BHJ}$ layer. Overall, $\mathrm{CuI}$ is a non-toxic, cost effective competitor, very easy to process even at room temperature and robust and reproducible over a broad range of processing and post-processing conditions, making it a suitable candidate for development of higher performance organic solar cells.

\section{Acknowledgements}

The authors would like to thank Prof. Thomas D. Anthopoulos for useful discussion on CuI properties, Mr. Mahmoud Abdul Hamid and Mr. Emanuele Aresu for their synthetic contributions and the preparation of the PBDTTPD polymer used in this study, Mr. Long Chen for help with acquisition of AFM data at KAUST, Prof. Yu Han for help with acquisition of UV-Vis absorption spectra at KAUST and Mr. Yangqin Gao for help of fabrication of the aperture. Part of this work was supported by the KAUST Office of Competitive Research.

\section{Materials and Methods:}

Solution preparation and thin film processing: The solution preparation was conducted under inert atmosphere inside a nitrogen glove box. CuI solutions were prepared by dissolving $\mathrm{CuI}$ powder ( $>99.5 \%$, Sigma-Aldrich) into solvents dipropyl sulfide (97\%, Sigma-Aldrich) or acetonitrile (anhydrous, 99.8\%, Sigma-Aldrich) with a concentration of $15 \mathrm{mg} / \mathrm{mL}$. Asprepared solutions were then stirred overnight at room temperature before use. Materials P3HT (445703, Sigma-Aldrich, $\mathrm{Mw}=68 \mathrm{kDa}$ ), $\mathrm{PC}_{60} \mathrm{BM} / \mathrm{PC}_{70} \mathrm{BM}$ (American dye source), PTB7 (1material), and PTB7-Th (1-material) were used as received. PBDTTPD was synthesized as reported in ref.40. The $\mathrm{P} 3 \mathrm{HT}: \mathrm{PC}_{60} \mathrm{BM}(1: 1, \mathrm{wt} / \mathrm{wt})$ solution was prepared in oDCB (anhydrous, 
$99 \%$, Sigma-Aldrich) with total concentration of $50 \mathrm{mg} / \mathrm{mL}$ followed by stirring overnight at $60^{\circ} \mathrm{C}$. The $\mathrm{PTB} 7: \mathrm{PC}_{70} \mathrm{BM}(2: 3, \mathrm{wt} / \mathrm{wt})$ solution was prepared in chlorobenzene (containing $3 \%$ (v/v) of 1,8-diiodooctane (DIO) additive) with total concentration of $25 \mathrm{mg} / \mathrm{mL}$ followed by stirring overnight at $60{ }^{\circ} \mathrm{C}$. The $\mathrm{PTB} 7-\mathrm{Th}: \mathrm{PC}_{70} \mathrm{BM}(2: 3$, wt/wt) solution was prepared in chlorobenzene (3\% v/v DIO as additive) with total concentration of $25 \mathrm{mg} / \mathrm{mL}$ followed by stirring overnight at $60{ }^{\circ} \mathrm{C}$. The PBDTTPD: $\mathrm{PC}_{70} \mathrm{BM}(2: 3 \mathrm{wt} / \mathrm{wt})$ solution was prepared in chlorobenzene $(5 \%(\mathrm{v} / \mathrm{v})$ 1-chloronaphtalene $(\mathrm{CN})$ as additive) with a concentration of 20 $\mathrm{mg} / \mathrm{mL}$ followed by stirring overnight at $115^{\circ} \mathrm{C}$. ITO/glass $\left(15 \Omega \mathrm{sq}^{-1}\right.$, ITO thickness $\left.140 \mathrm{~nm}\right)$ substrates were cleaned through sequential sonication in sodium dodecyl sulfate (SDS) solution, deionized water, acetone and isopropanol for 15 min each. Substrate cleaning was completed through exposure to oxygen plasma for $10 \mathrm{~min}$. The cleaned ITO/glass substrates were immediately spin coated with PEDOT:PSS (Clevious, AI4083) at $4000 \mathrm{rpm}$ for $30 \mathrm{sec}$ in ambient atmosphere or moved to the nitrogen glove box and spin coated with $\mathrm{CuI}$ with spinning speed ranging from $500 \mathrm{rpm}$ to $5000 \mathrm{rpm}$ to get film thickness ranging between $20 \mathrm{~nm}$ down to $7 \mathrm{~nm}$. The as-cast PEDOT:PSS films were then baked at $140{ }^{\circ} \mathrm{C}$ for $10 \mathrm{~min}$ in ambient atmosphere to dry water. The as-cast $\mathrm{CuI}$ films can be dried at ambient temperature to yield good solar cells, but were baked at $60{ }^{\circ} \mathrm{C}$ for $2 \mathrm{~min}$ to dry the solvent faster. The P3HT: $\mathrm{PC}_{60} \mathrm{BM}$ solutions were spin-coated onto the HTLs with a speed of $900 \mathrm{rpm}$ for $45 \mathrm{sec}$ followed by keeping films in covered petri dish overnight. The films were annealed at $130{ }^{\circ} \mathrm{C}$ for $10 \mathrm{~min}$ prior to placing into the vacuum evaporator for device fabrication. The PTB7:PC ${ }_{70} \mathrm{BM}$ solution and $\mathrm{PTB} 7-\mathrm{Th}: \mathrm{PC}_{70} \mathrm{BM}$ solution were spin-coated onto the HTLs with a speed of 1000 rpm for $50 \mathrm{sec}$. The PBDTTPD: $\mathrm{PC}_{70} \mathrm{BM}$ solution $\left(90{ }^{\circ} \mathrm{C}\right)$ was spin-coated with thickness of of 100 to $120 \mathrm{~nm}$. Device fabrication was completed by placing the samples in a high vacuum metal evaporator in the $\mathrm{N}_{2}$-filled glove-box and by depositing electrodes of $\mathrm{Ca}$ 
$(10 \mathrm{~nm}) / \mathrm{Al}(80 \mathrm{~nm})$ for P3HT:PC ${ }_{60} \mathrm{BM}$ devices and $\mathrm{Ca}(15 \mathrm{~nm}) / \mathrm{Al}(80 \mathrm{~nm})$ for other polymer based devices. The active area of the devices was defined as $0.1 \mathrm{~cm}^{2}$ by using aperture. The current density-voltage characteristics of the photovoltaic cells were measured using a Keithley 2400 under a simulated AM $1.5 \mathrm{G}$ solar irradiation at $100 \mathrm{~mW} \mathrm{~cm}{ }^{-2}$. The external quantum efficiency (EQE) was recorded by Oriel Quantum Efficiency Measurement Kit (Newport).

$X$-ray and ultraviolet photoelectron spectroscopies (XPS/UPS): The XPS measurements were performed in ultrahigh vacuum chamber (Omicron NanoTechnology, Taunusstein, Germany) equipped with a monochromatic Al source $(1486.7 \mathrm{eV})$ and a hemispherical energy analyzer EIS-Sphera (Omicron NanoTechnology, Taunusstein, Germany). The He (I) UV source operating at $21.22 \mathrm{eV}$ was a HIS 13 capillary discharge lamp. Pass energies of $20 \mathrm{eV}$ and $3 \mathrm{eV}$ were applied during the XPS and UPS measurements, respectively. A base pressure of about $\sim 10^{-10}$ mbar was maintained throughout all experiments. Vacuum-deposition of CuI was conducted in a high vacuum metal evaporator in the nitrogen glove box. A film thickness of about $11 \mathrm{~nm}$ was chosen to minimize charging during UPS measurements. Both solutionprocessed and vacuum-deposited CuI films were transferred from the nitrogen glove box to the UHV chamber without exposure to air using a specially designed vacuum suitcase equipped with a turbomolecular pump.

Electron microscopy: A transmission electron microscope operating at $300 \mathrm{kV}$ (Titan Cryo Twin, FEI Company, Hillsboro, OR) was used to acquire cross-sectional micrographs using a 4k x 4k charged couple device (CCD) camera model US4000 and an energy filter model GIF Tridiem from Gatan, Inc. (Gatan Inc., Pleasanton, CA). The GIF was utilized in energy-filtered TEM (EF-TEM) mode to image the Carbon and Sulfur distribution in the sample. The Carbon edge located at $284 \mathrm{eV}$ and Sulfur edge at $165 \mathrm{eV}$ were selected to generate the EF-TEM maps 
using a 3-window method. Samples were prepared on a Helios 400s focused ion beam (FIB; FEI Company), foils were lifted out in situ using an Omniprobe nanomanipulator (AutoProbe300). Electron beam assisted carbon and platinum deposition was performed on the sample surface to protect the thin film surface against the ion beam bombardment during ion beam milling. Ga ion beam $(30 \mathrm{kV}, 9 \mathrm{nA})$ was first used to cut the sample from the bulk $(30 \mathrm{kV}$, $9 \mathrm{nA}$ ), after which it was attached to a $\mathrm{Cu}$ grid using a lift-out method. The sample was subsequently thinned down to ca. $50 \mathrm{~nm}$ thickness $(30 \mathrm{kV}, 93 \mathrm{pA})$ and cleaned $(2 \mathrm{kV}, 28 \mathrm{pA})$ to get rid of areas of the sample damaged during the thinning process. Samples for plan-view were prepared by floating the thin film in water and picking it up using a 400 mesh copper grid.

Grazing incidence wide angle X-ray scattering (GIWAXS) measurements were performed at D-line at the Cornell High Energy Synchrotron Source (CHESS). The wavelength of the X-rays was $1.157 \AA$ with a bandwidth $\Delta \lambda / \lambda$ of $1.5 \%$. The scattering signal was collected by an area CCD detector detector with a pixel size of $46.9 \mu \mathrm{m}$ by $46.9 \mu \mathrm{m}$ placed at $91 \mathrm{~mm}$ away from the sample position. The incident angle of the X-ray beam was at 0.15 degree and the integration time was $1 \mathrm{~s}$.

$X$-ray diffraction (XRD) measurements were carried out in a $\theta-2 \theta$ configuration with a scanning interval of $2 \theta$ between $20^{\circ}$ and $60^{\circ}$ on a Bruker D8 Discover (X-ray Source: $\mathrm{Cu} \mathrm{K} \alpha ; \lambda$ $=1.54 \AA$ ).

Optical metrology: UV-Visible transmission and absorption spectra were acquired on a Cary 5000 (Varian) instrument. Variable Angle Spectroscopic Ellipsometry (VASE) was performed using a M-2000XI rotating compensator (J. A. Woollam Co., Inc) to determine the thickness and the optical properties. The substrates used for VASE measurements were $\mathrm{Si}(100)$ with a $300 \mathrm{~nm}$ thermal oxide. VASE spectra ranging from $210 \mathrm{~nm}$ to $1689 \mathrm{~nm}$ were recorded at 8 different angles of incidence with respect to the substrate normal from $45^{\circ}$ to $79^{\circ}$, with $5^{\circ}$ 
increment. For the purpose of model fitting, the CuI HTL was first regarded as isotropic material with refractive index modeled using a Cauchy dispersion over the transparent range from 500 to $1689 \mathrm{~nm}$. Upon determining the CuI film thickness in the transparent range, a Kramers-Kronig consistent spline method was used to determine $\mathrm{n}$ and $\mathrm{k}$ below $500 \mathrm{~nm}$. For the PEDOT:PSS HTL case, the film was regarded isotropic material with optical modelled by using the Tauc-Lorenz oscillator model to generate thickness as well as $\mathrm{n}$ and $\mathrm{k}$. A two-layer model, the bottom layer HTLs with obtained thickness and optical functions as well as the top unknown active layers, was established for extracting the optical functions and thickness of the active layers. The optical properties of the active layers were modelled assuming a Cauchy dispersion relation and uniaxial anisotropy above the bandgap of the donor. Using the same method as described for $\mathrm{CuI}$ optical fitting, the in-plane and out-of-plane optical properties of the P3HT:PCBM blend were deduced. All data analysis was performed using the EASETM and WVASE32 software packages (J. A. Woollam Co., Inc).

Resistance of fresh prepared CuI and PEDOT:PSS film were measured by using the LOM510A Micro-Ohmmeter in $\mathrm{N}_{2}$ filled glove-box.

Atomic force microscopy: The surface topography of the samples was analyzed by atomic force microscopy in tapping mode using an Agilent 5400 SPM. 
Figures and captions

(a)

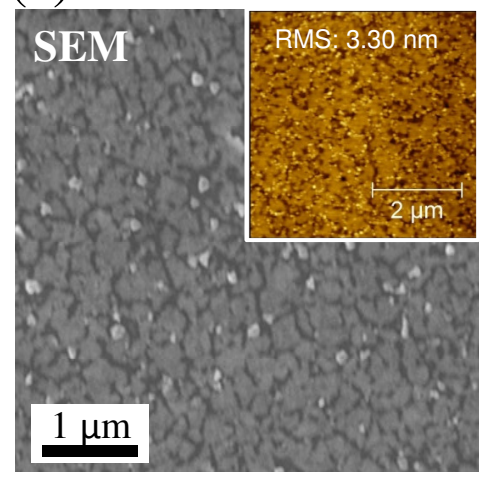

(d)

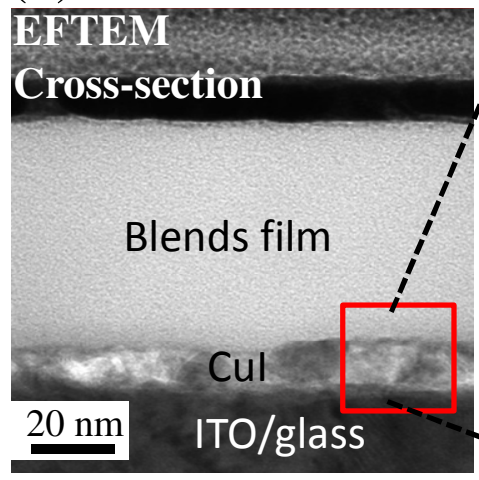

(b)

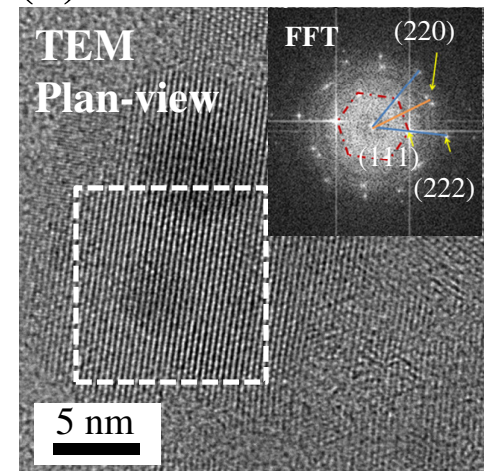

(e)

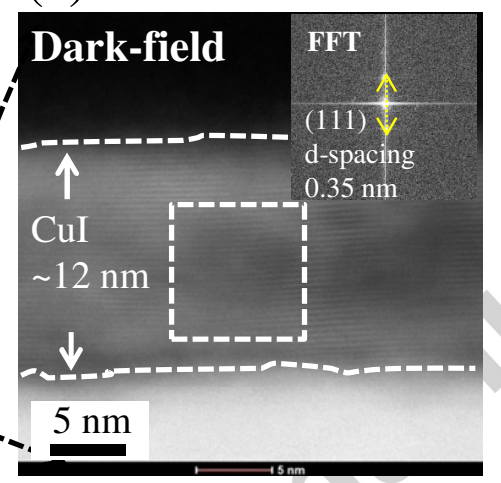

(c)

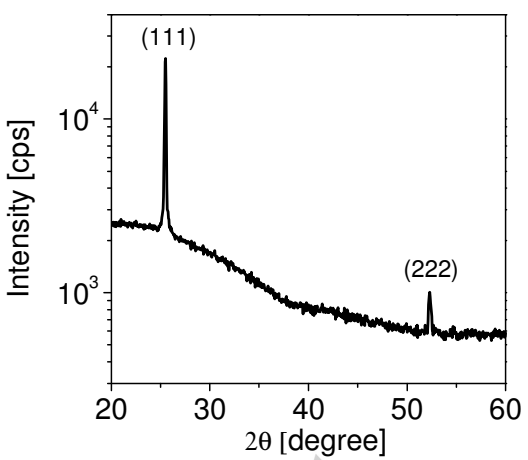

(f)

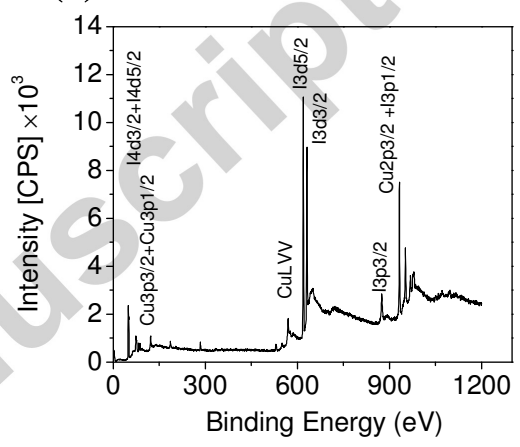

Figure 1. (a) SEM image of a solution-processed CuI film on ITO, inset showing atomic force micrographs of $\mathrm{CuI}$ film. (b) plan-view bright-field high resolution TEM (HRTEM) on CuI film deposited on a TEM copper grid. (c) X-ray diffraction (XRD) spectrum of the solutionprocessed CuI film ( 12 nm) showing (111) and (222) crystalline planes in $\gamma$-phase. (d,e) crosssectional TEM of a CuI film sandwiched between ITO and the organic photoactive layer in an actual device shown on the left. (f) X-ray photoelectron spectroscopy (XPS) of the solutionprocessed CuI film $(\sim 12 \mathrm{~nm})$. The spectrum shows that the film mainly contains copper and iodine. 
Table 1. The detailed parameters of X-ray photoelectron spectroscopy of solution-processed $\mathrm{CuI}$ film $(\sim 12 \mathrm{~nm})$. Concentration ratio of copper and iodine elements is 1:1, suggesting no elemental loss.

\begin{tabular}{llllcl}
\hline Elements & $\begin{array}{l}\text { Peak used for } \\
\text { quantification }\end{array}$ & $\begin{array}{c}\text { Peak Position } \\
{[\mathrm{eV}]}\end{array}$ & R.S.F. & $\begin{array}{c}\text { Area } \\
\text { [a.u.] }\end{array}$ & $\begin{array}{c}\text { Conc. } \\
\text { [at.\%] }\end{array}$ \\
\hline Iodine & I3d & 619.45 & 33.6 & 24.6 & 49.5 \\
Copper & Cu3p & 932.35 & 25.4 & 19.0 & 50.5 \\
\hline
\end{tabular}

(a)
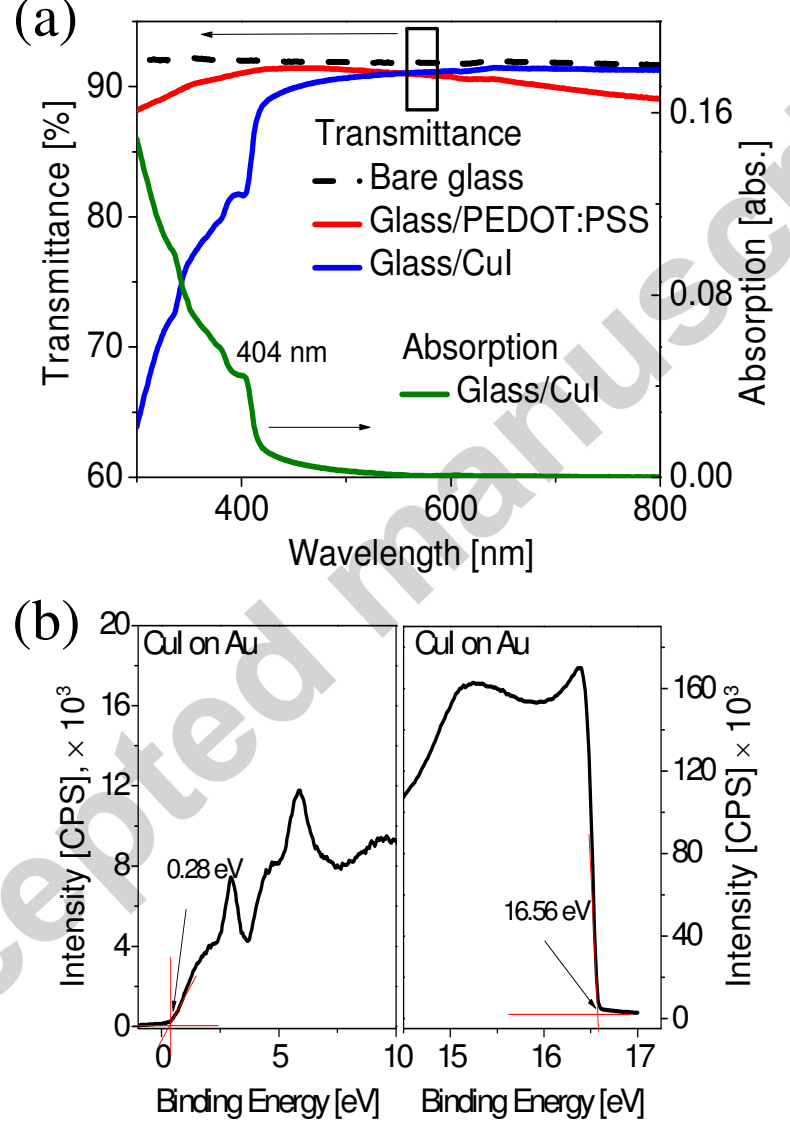

Figure 2. (a) Optical transmission spectra of a CuI film ( 12 nm) and PEDOT:PSS ( 22 nm) on bare glass and the UV-visible absorption spectrum of the $\mathrm{CuI}$ film. (b) Ultraviolet photoelectron spectroscopy (UPS) showing valence band onset at $0.28 \mathrm{eV}\left(\mathrm{E}_{\mathrm{c}}:-4.9 \mathrm{eV}\right)$ and Secondary eletrons cut-off at $16.56 \mathrm{eV}(\mathrm{WF}:-4.7 \mathrm{eV})$ for the solution-procesed CuI film $(\sim 12$ $\mathrm{nm})$. 
Table 2. Photovoltaic parameters under AM1.5G solar spectrum with light intensity of 100 $\mathrm{mW} / \mathrm{cm}^{2}$ for P3HT:PC 60 BM organic solar cells. The device structure is $\mathrm{ITO} / \mathrm{HTL} / \mathrm{BHJ} / \mathrm{Ca} / \mathrm{Al}$, where HTL is either PEDOT:PSS or CuI. CuI ${ }^{[\mathrm{a}]}$ and $\mathrm{CuI}{ }^{[\mathrm{b}]}$ refer to the solution-processed $(\sim 12$ $\mathrm{nm})$ and vacuum-deposited CuI film $(\sim 11 \mathrm{~nm})$, respectively. The results are expressed in terms of the average and standard deviation from $\sim 5$ devices.

\begin{tabular}{lcccc}
\hline \multicolumn{1}{c}{ HTL } & $\begin{array}{c}\mathbf{J}_{\text {sc }} \\
{\left[\mathbf{m A} / \mathbf{c m}^{2}\right]}\end{array}$ & $\begin{array}{c}\mathbf{V}_{\text {oc }} \\
{[\mathbf{V}]}\end{array}$ & $\begin{array}{c}\text { FF } \\
{[\%]}\end{array}$ & $\begin{array}{c}\text { PCE (PCE } \\
\text { max }\end{array}$ \\
& $9.28 \pm 0.11$ & $0.61 \pm 0.01$ & $64.8 \pm 0.21$ & $3.65 \pm 0.04(3.7)$ \\
\hline PEDOT:PSS & $9.42 \pm 0.07$ & $0.59 \pm 0.01$ & $70.9 \pm 0.12$ & $3.94 \pm 0.03(4.0)$ \\
CuI $^{\text {[a] }}$ & $9.06 \pm 0.07$ & $0.59 \pm 0.01$ & $72.4 \pm 0.08$ & $3.85 \pm 0.02(3.9)$ \\
CuI $^{[\mathbf{b}]}$ & & & & \\
\hline
\end{tabular}

(a)

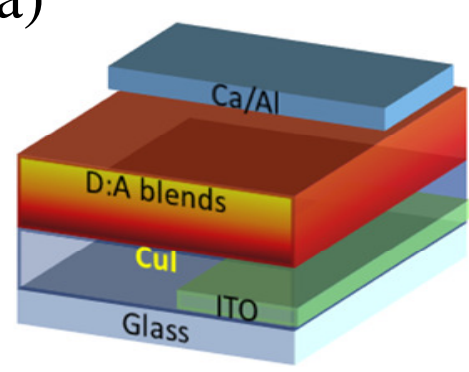

(d)

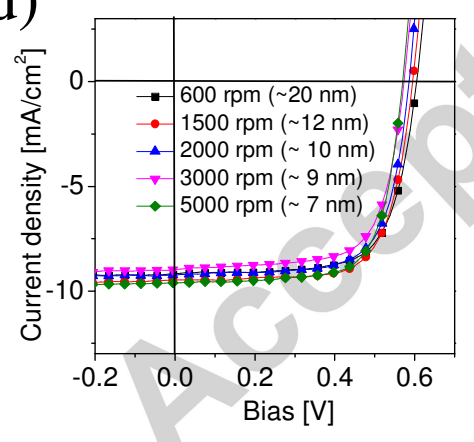

(b)

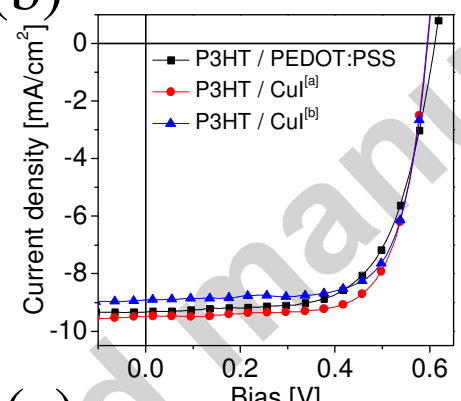

(e)

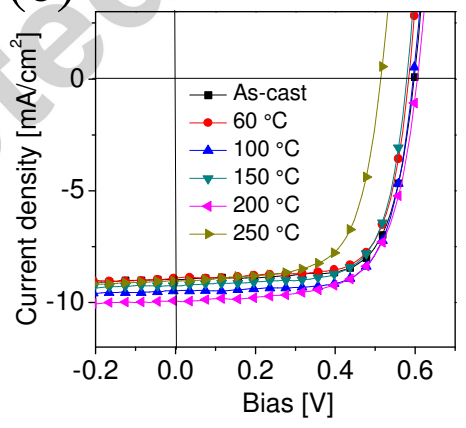

(c)

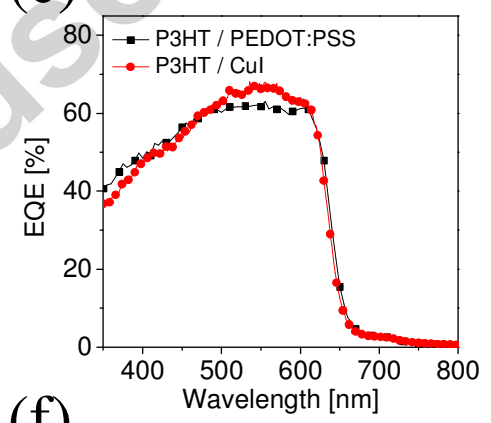

(f)

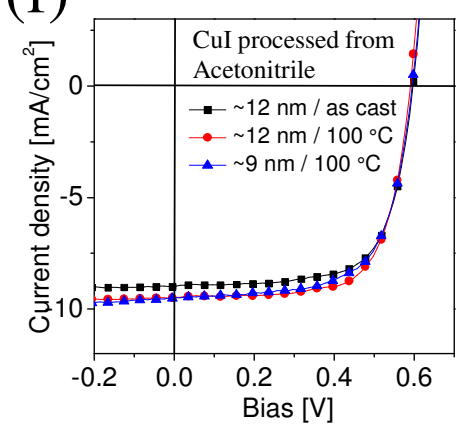

Figure 3. (a) Standard configuration of polymer:fullerene devices with CuI HTL at the bottom.

(b) $J-V$ plots under the illumination of AM $1.5 \mathrm{G}, 100 \mathrm{~mW} / \mathrm{cm}^{2}$, and (c) EQE spectra for the P3HT:PC ${ }_{60} \mathrm{BM}$ solar cells with PEDOT:PSS or $\mathrm{CuI}$ as $\mathrm{HTL} \mathrm{CuI}^{[\mathrm{a}]}$ and $\mathrm{CuI}^{[\mathrm{b}]}$ refer to the solution-processed $(\sim 12 \mathrm{~nm})$ and vacuum-deposited $(\sim 11 \mathrm{~nm})$ CuI films, respectively. (d-f) $J-V$ plots of $\mathrm{CuI}$ based P3HT:PC ${ }_{60} \mathrm{BM}$ devices showing the effect of $\mathrm{CuI}$ thickness, post-processing 
temperature of $\mathrm{CuI}$ and choice of solvent of $\mathrm{CuI}$ solution (acetonitrile) on the performance of P3HT:PC ${ }_{60} \mathrm{BM}$ solar cells, respectively.

Table 3. Effect of $\mathrm{CuI}$ thickness, post-processing temperature of $\mathrm{CuI}$ and choice of solvent of $\mathrm{CuI}$ solution (acetonitrile) on the performance of $\mathrm{P} 3 \mathrm{HT}: \mathrm{PC}_{60} \mathrm{BM}$ solar cells. [i]: note that the maximum thickness of $19.2 \mathrm{~nm}$ is obtained by spin-coating from a saturated solution with low speed $(600 \mathrm{rpm})$ for $60 \mathrm{sec}$.

\begin{tabular}{ccccccc}
\hline Solvent & $\begin{array}{c}\text { Temperature } \\
{\left[{ }^{\mathbf{}} \mathbf{C}\right]}\end{array}$ & $\begin{array}{c}\text { Thickness } \\
{[\mathbf{n m}]}\end{array}$ & $\begin{array}{c}\mathbf{J}_{\text {sc }} \\
{\left[\mathbf{m A} / \mathbf{c m}^{2}\right]}\end{array}$ & $\begin{array}{c}\mathbf{V}_{\text {oc }} \\
{[\mathbf{V}]}\end{array}$ & $\begin{array}{c}\mathbf{F F} \\
{[\%]}\end{array}$ & $\begin{array}{c}\text { PCE } \\
{[\%]}\end{array}$ \\
\hline DPS & 25 & $19.2^{[1]}$ & $9.29 \pm 0.05$ & $0.60 \pm 0.02$ & $69.9 \pm 0.30$ & $3.90 \pm 0.00$ \\
DPS & 25 & 11.6 & $9.42 \pm 0.07$ & $0.59 \pm 0.01$ & $70.9 \pm 0.12$ & $3.94 \pm 0.03$ \\
DPS & 25 & 10.1 & $9.00 \pm 0.20$ & $0.58 \pm 0.01$ & $70.1 \pm 0.30$ & $3.70 \pm 0.08$ \\
DPS & 25 & 9.3 & $9.16 \pm 0.20$ & $0.57 \pm 0.01$ & $70.1 \pm 0.45$ & $3.70 \pm 0.09$ \\
DPS & 25 & 7.0 & $9.55 \pm 0.01$ & $0.57 \pm 0.01$ & $70.4 \pm 1.04$ & $3.85 \pm 0.04$ \\
DPS & 60 & 11.6 & $8.84 \pm 0.11$ & $0.58 \pm 0.02$ & $71.2 \pm 0.09$ & $3.65 \pm 0.15$ \\
DPS & 100 & 11.6 & $8.91 \pm 0.05$ & $0.60 \pm 0.01$ & $71.0 \pm 0.18$ & $3.75 \pm 0.18$ \\
DPS & 150 & 11.6 & $9.21 \pm 0.20$ & $0.58 \pm 0.01$ & $70.3 \pm 0.20$ & $3.80 \pm 0.10$ \\
DPS & 200 & 11.6 & $9.92 \pm 0.02$ & $0.60 \pm 0.01$ & $65.4 \pm 0.22$ & $3.95 \pm 0.09$ \\
DPS & 250 & 11.6 & $8.93 \pm 0.24$ & $0.50 \pm 0.01$ & $65.9 \pm 0.17$ & $2.96 \pm 0.04$ \\
ACN & 25 & 12.1 & $8.81 \pm 0.12$ & $0.60 \pm 0.01$ & $68.7 \pm 0.26$ & $3.65 \pm 0.13$ \\
ACN & 100 & 12.1 & $9.23 \pm 0.11$ & $0.59 \pm 0.01$ & $69.6 \pm 0.14$ & $3.80 \pm 0.19$ \\
ACN & 100 & 8.5 & $9.38 \pm 0.10$ & $0.59 \pm 0.02$ & $68.7 \pm 0.22$ & $3.78 \pm 0.14$ \\
\hline
\end{tabular}




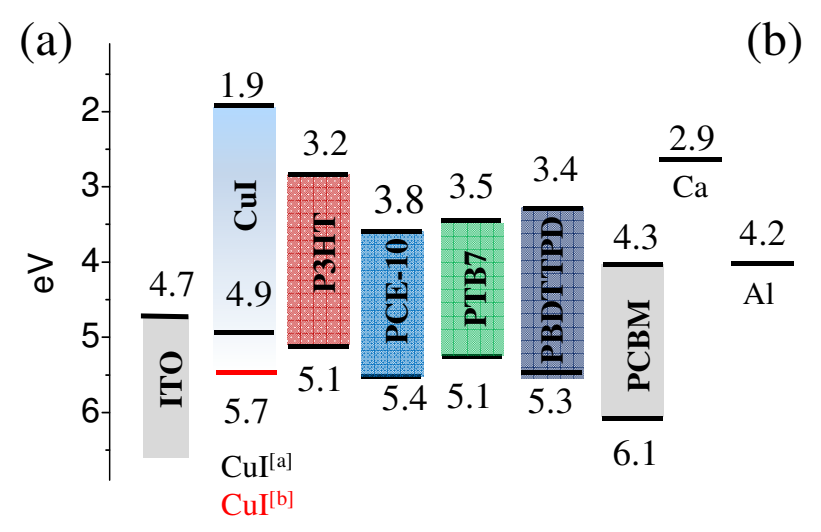

(b)

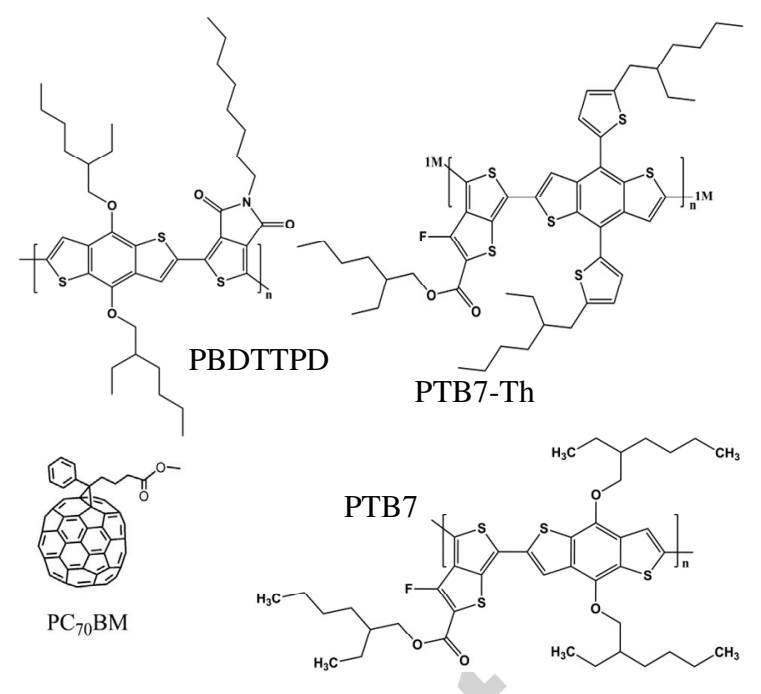

Figure 4. (a) Energy level diagrams of the complete device, where $\mathrm{CuI}^{[\mathrm{a}]}$ and $\mathrm{CuI}^{[\mathrm{b}]}$ refer to solution-processed $(\sim 12 \mathrm{~nm})$ and vacuum-deposited $(\sim 11 \mathrm{~nm}) \mathrm{CuI}$ films, respectively. Valence band edges of $\mathrm{CuI}^{[\mathrm{a}]}$ and $\mathrm{CuI}^{[\mathrm{b}]}$ were measured by UPS and the conduction band edge was estimated from the estimated direct optical band gap $(2.96 \mathrm{eV})$. (b) Molecular structures of different highly efficient donor:acceptor systems, PTB7, PBDTTPD, PTB7-Th, and PC 70 BM. 
(a)

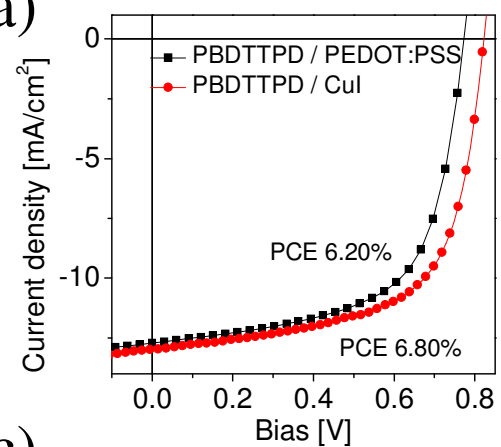

(c)

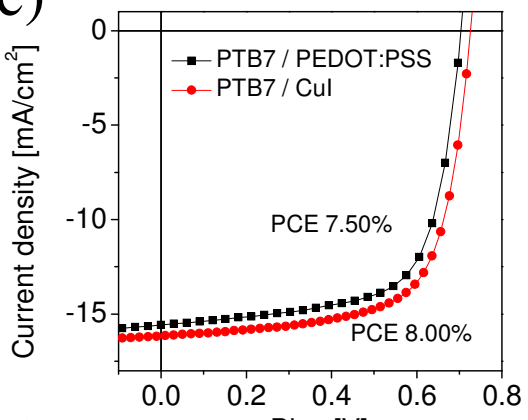

(e)

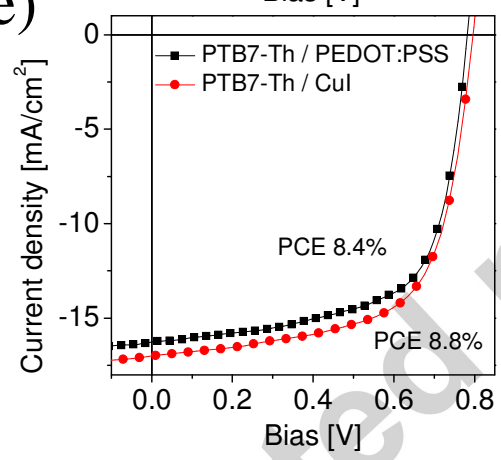

(b)

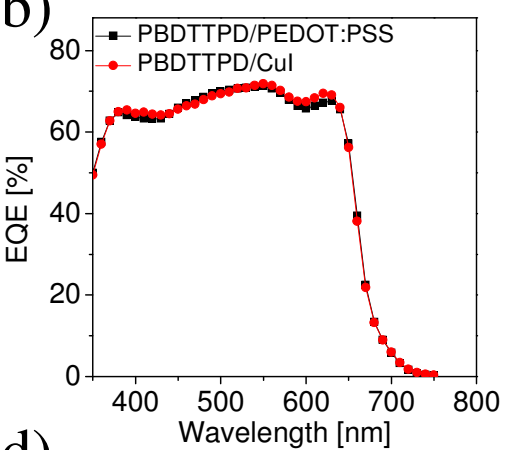

(d)

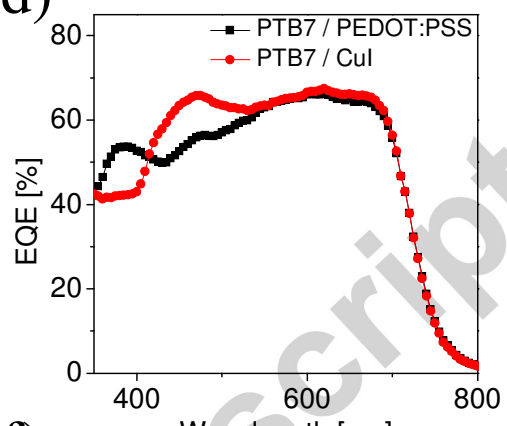

(f)

Wavelength [nm]

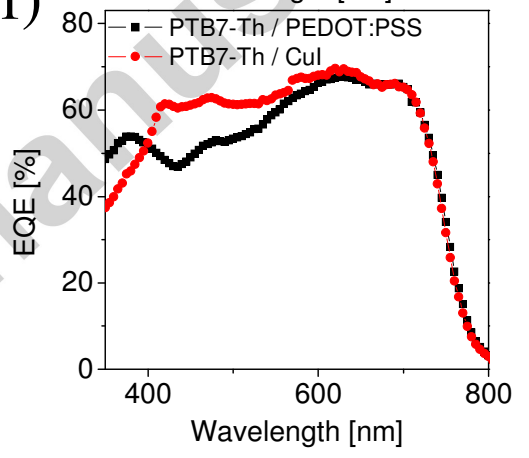

Figure 5. (a,c,e) $J-V$ plots under the illumination of AM $1.5 \mathrm{G}$ with light intensity of 100 $\mathrm{mW} / \mathrm{cm}^{2}$ and $(\mathrm{b}, \mathrm{d}, \mathrm{f}) \mathrm{EQE}$ spectra for the $\mathrm{PTB} 7: \mathrm{PC}_{70} \mathrm{BM}, \mathrm{PTB} 7-\mathrm{Th}: \mathrm{PC}_{70} \mathrm{BM}$ devices with PEDOT:PSS and CuI as HTL. 
Table 4. Photovoltaic parameters under AM 1.5G solar spectrum with light intensity of 100 $\mathrm{mW} / \mathrm{cm}^{2}$ for PBDTTPT:PC $70 \mathrm{BM}, \mathrm{PTB} 7: \mathrm{PC}_{70} \mathrm{BM}$ and PTB7-Th:PC $70 \mathrm{BM}$ solar cells. The device structure is ITO/HTL/donor:acceptor/Ca/Al, where HTL is either PEDOT:PSS or CuI, both solution processed. The results are expressed in terms of the average and standard deviation calculated from $\sim 5$ devices.

\begin{tabular}{llrccc}
\hline \multicolumn{1}{c}{ Donor } & HTL & $\begin{array}{c}\mathbf{J}_{\text {sc }} \\
{\left[\mathbf{m A} / \mathbf{c m}^{2}\right]}\end{array}$ & $\begin{array}{c}\mathbf{V}_{\text {oc }} \\
{[\mathbf{V}]}\end{array}$ & $\begin{array}{c}\text { FF } \\
{[\%]}\end{array}$ & $\begin{array}{c}\text { PCE (PCE } \\
{[\mathbf{\%})}\end{array}$ \\
\hline PBDTTPT & PEDOT & $12.61 \pm 0.32$ & $0.77 \pm 0.08$ & $62.7 \pm 0.18$ & $6.00 \pm 0.12(6.2)$ \\
PBDTTPT & CuI & $12.87 \pm 0.26$ & $0.82 \pm 0.05$ & $63.4 \pm 0.32$ & $6.32 \pm 0.30(6.8)$ \\
PTB7 & PEDOT & $15.72 \pm 0.16$ & $0.70 \pm 0.01$ & $68.0 \pm 0.26$ & $7.31 \pm 0.17(7.5)$ \\
PTB7 & CuI & $15.85 \pm 0.29$ & $0.71 \pm 0.01$ & $66.2 \pm 0.18$ & $7.70 \pm 0.25(8.0)$ \\
PTB7-Th & PEDOT & $16.27 \pm 0.25$ & $0.78 \pm 0.01$ & $65.2 \pm 0.92$ & $8.14 \pm 0.20(8.4)$ \\
PTB7-Th & CuI & $17.08 \pm 0.42$ & $0.79 \pm 0.01$ & $63.9 \pm 1.00$ & $8.33 \pm 0.34(8.8)$ \\
\hline
\end{tabular}
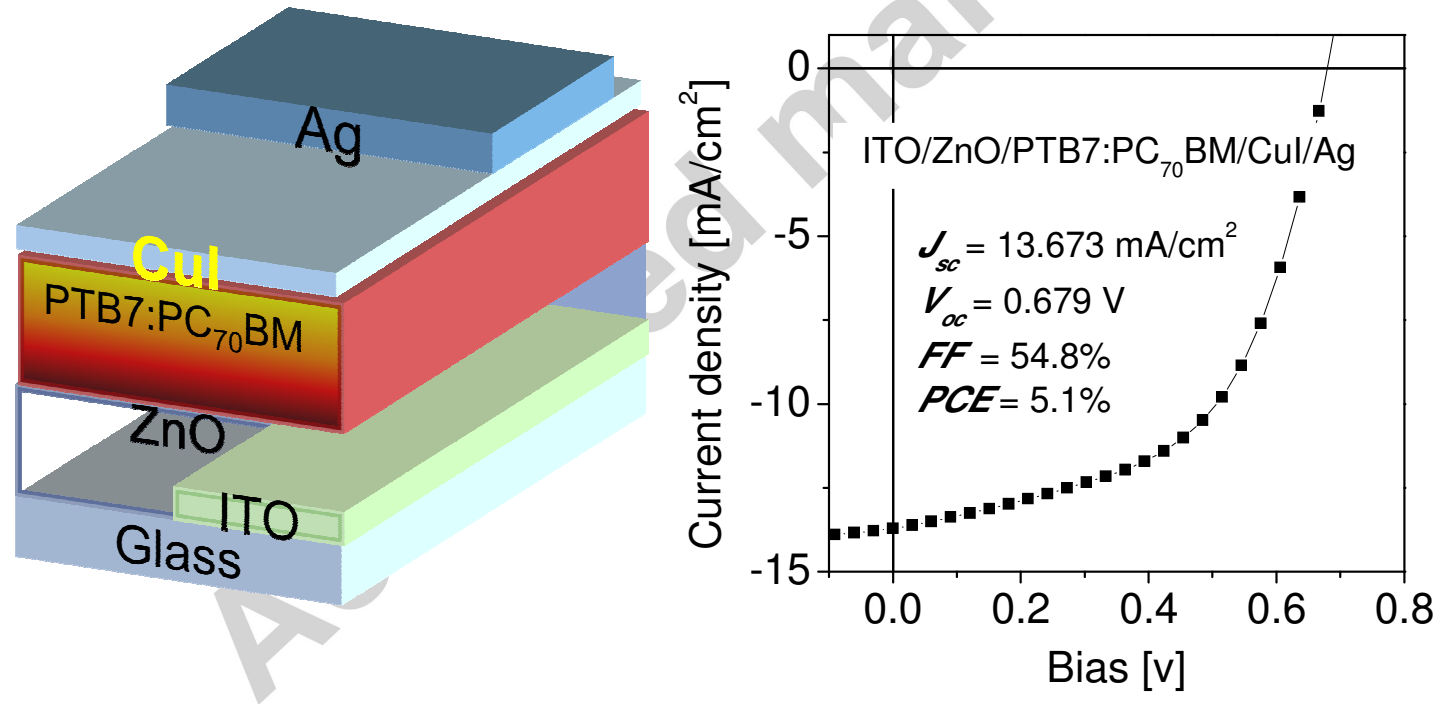

Figure 6. Configuration of an inverted device (left) and $J-V$ plots (right) of $\mathrm{PTB} 7: \mathrm{PC}_{70} \mathrm{BM}$ inverted solar cell based on low temperature solution-processed $\mathrm{ZnO}$ and room temperature solution-processed $\mathrm{CuI}$ as bottom ETL and top HTL, respectively. 


\section{References}

[1] Z. He, C. Zhong, S. Su, M. Xu, H. Wu, Y. Cao, Nat Photonics, 6 (2012) 591.

[2] R. Po, C. Carbonera, A. Bernardi, N. Camaioni, Energy Environ. Sci., 4 (2011) 285.

[3] L.K. Jagadamma, M.Al-Senani, A.El-Labban, I. Gereige, G.O.Ngongang Ndjawa, J.C.D. Faria, T. Kim, K. Zhao, F. Cruciani, D.H. Anjum, M.A. McLachlan, P.M. Beaujuge, A. Amassian, Adv. Energy Mater. (2015) DOI:10.1002/aenm.201500204.

[4] M.P. de Jong, L.J. van Ijzendoorn, M.J.A. de Voigt, Appl. Phys. Lett. 77(2000) 2255.

[5] Y. Sun, C.J.Takacs, S.R. Cowan, J.H. Seo, X. Gong, A. Roy, A.J.Heeger, Adv. Mater. 23 (2011) 2226.

[6] A.W.Hains, A.B.F. Martinson, M.D.Irwin, H. Yan, T.J.Marks, Polym. Mater. Sci. Eng. 96 (2007) 814.

[7] K.X.Steirer, P. F.Ndione, N.E. Widjonarko, M.T. Lloyd, J. Meyer, E.L. Ratcliff, A. Kahn, N.R. Armstrong, C.J. Curtis, D.S. Ginley, J.J. Berry, D.C. Olson, Adv. Energy Mater. 1 (2011) 813.

[8] S.R. Hammond, J. Meyer, N.E. Widjonarko, P.F. Ndione, A.K. Sigdel, A. Garcia, A. Miedaner, M.T. Lloyd, A. Kahn, D.S. Ginley, J.J. Berry, D.C. Olson, J. Mater. Chem., 22 (2012) 3249.

[9] H. Choi, B.S. Kim, M.J. Ko, D.K. Lee, H. Kim, S.H. Kim, K. Kim, Org. Electron.13 (2012) 959.

[10] J. Meyer, K. Zilberberg, T. Ried, A. Kahn, J. Appl. Phys. 110 (2011) 033710.

[11] J.R. Manders, S.W. Tsang, M.J. Hartel, T.H. Lai, S. Chen, C.M. Amb, J.R. Reynolds, F. So, Adv. Funct. Mater. 23 (2013) 2993.

[12] T. Yang, M. Wang, Y. Cao, F. Huang, L. Huang, J. Peng, X. Gong, S.Z.D. Cheng, Y. Cao, Adv. Energy Mater. 2 (2012) 523.

[13] K. Zilberberg, S. Trost, H. Schmidt, T. Riedl, Adv. Energy Mater. 1 (2011) 377.

[14] J. Meyer, S. Hamwi, M. Kröger, W. Kowalsky, T. Riedl, A. Kahn, Adv. Mater. 24( 2012) 5408.

[15] Z. Zhai, X. Huang, M. Xu, J. Yuan, J. Peng, W. Ma, Adv. Energy Mater. 3 (2013) 1614.

[16] F. Xie, W.C.H. Choy, C. Wang, X. Li, S. Zhang, J. Hou, Adv. Mater. 25 (2013) 2051.

[17] C.P. Chen, Y.D. Chen, S.C. Chuang, Adv. Mater. 23 (2011) 3859.

[18] M. Makha, L. Cattin, S.O. Djobo, N. Stephant, N. Langlois, B. Angleraud, M. Morsli, M. Addou, J.-C. Bern $\square$ de, Eur. Phys. J. Appl. Phys. 60 (2012) 31302.

[19] Y.H. Yan, Y.C. Liu, L. Fang, Z.C. Lu, Z.B. Li, S.X. Shao, Tras. Nonferrous Met. Soc. China 21 (2011) 359.

[20] A.R. Zainun, U.M. Noor, M. Ruso, Int. J. Phys. Sci. 6 (2011) 3993. 
[21] A.R. Zainun, M.H. Mama, U.M. Noor, M. Rusop, IOP Conf. Series.: Mater. Sci. Eng. 17 (2011) 012009.

[22] K. Tennakone, G.R.R.A. Kumra, A.R. Kumarasinghe, K.G.U. Wijayantha, P.M. Sirimanne, Semicond. Sci. Technol. 10 (1995) 1689.

[23] C.A.N. Fernando, I. Kumarawadu, Semicond. Sci. Technol. 15 (2000) 214.

[24] P.M. Sirimanne, T. Jeranko, P. Bogdanoff, S. Fiechter, H. Tributsch, Semicond. Sci. Technol. 18 (2003) 708.

[25] K. Tennakone, G.R.R.A. Kumara, I.R.M. Kottegoda, K.G.U. Wijayantha, Semicond. Sci. Technol. 12 (1997) 128.

[26] P.M. Sirimanne, M.K.I. Senevirathna, E.V.A. Premalal, P.K.D.D.P. Pitigala, Semicond. Sci. Technol. 21 (2006) 818 .

[27] M.N. Amalina, A.A.E. Najwa, M.H. Abdullah, M.Z. Musa, M. Rusop, IOP Conf. Series.: Mater. Sci. Eng. 46 (2013) 012012.

[28] B.P. Rand, D. Cheyns, K. Vasseur, N.C. Giebink, S. Mothy, Y. Yi, V. Coropceanu, D. Beljonne, J. Cornil, J.-L. Brédas, J. Genoe, Adv. Funct. Mater. 22 (2012) 2987.

[29] Y. Zhou, T. Taima, T. Miyadera, T. Yamanari, M. Kitamura, K. Nakatsu, Y. Yoshida, Nano Lett. 12 (2012) 4146.

[30] C.H. Cheng, J. Wang, G.T. Du, S.H. Shi, Z.J. Du, Z.Q. Fan, J.M. Bian, M.S. Wang, Appl. Phys. Lett. 97 (2010) 083305.

[31] S. Shao, J. Liu, J. Zhang, B. Zhang, Z. Xie, Y. Geng, L. Wang, ACS Appl. Mater. Interfaces 4 (2012) 5704.

[32] W. Sun, H. Peng, Y. Li, W. Yan, Z. Liu, Z. Bian, C. Huang, J. Phys. Chem. C 118 (2014) 16806.

[33] P.P. Zamora, F.R. Díaz, M.A.d. Valle, L. Cattin, G. Louarn, J.C. Bernède, Natural Resources, 4 (2013) 123.

[34] P. Pattanasattayavong, G.O. Ngongang Ndjawa, K. Zhao, K. W. Chou, N. Yaacobi-Gross, B.C. O’Regan, A. Amassian, T.D. Anthopoulos, Chem. Commun., 49 (2013) 4154.

[35] P. Pattanasattayavong, N. Yaacobi-Gross, K. Zhao, G.O. Ngongang Ndjawa, J. Li, F. Yan, B.C. O’Regan, A. Amassian, T.D. Anthopoulos, Adv. Mater. 25 (2013) 1504.

[36] N. Yaacobi-Gross, N.D. Treat, P. Pattanasattayavong, H. Faber, A.K. Perumal, N. Stingelin, D.D.C. Bradley, P.N. Stavrinou, M. Heeney, T.D. Anthopoulos, Adv. Energy Mater. 5 (2015) 1401529. 
[37] D.A. Keen, S. Hull, J. Phys.: Condens. Matter 7 (1995) 1793.

[38] M.N. Amalina, N.A. Rasheid, M. Rusop, J. Nanomater. 637637 (2012) 1.

[39] S. Liao, H. Huo, Y. Cheng, S. Chen, Adv. Mater. 25 (2013) 4766.

[40] Z. Liang, Q. Zhang, O. Wiranwetchayan, J. Xi, Z. Yang, K. Park, C. Li, G. Cao, Adv. Funct. Mater. 22 (2012) 2194.

[41] Y.-C. Tseng, A.U. Mane, J.W. Elam, S. Darling, Sol Energ Mate Sol C 99 (2012) 235.

[42] L.K. Jagadamma, M. Abdelsamie, A.E. Labban, E. Aresu, G.O. Ngongang Ndjawa, D.H. Anjum, D. Cha, P.M. Beaujugeab, A. Amassian, J. Mater. Chem. A, 2 (2014) 13321.

[43] R. Li, H.U. Khan, M.M. Payne, D.-M. Smilgies, J.E. Anthony, A. Amassian, Adv. Funct. Mater. 23 (2013) 291.

[44] K. Zhao, H. U. Khan, R. Li, Y. Su, A. Amassian, Adv. Func. Mater. 23 (2013) 6024.

[45] K.W. Chou, B. Yan, R. Li, E.Q. Li, K. Zhao, D.H. Anjum, S. Alvarez, R. Gassaway, A. Biocca, S.T. Thoroddsen, A. Hexemer, A. Amassian, Adv. Mater. 25 (2013) 1923.

[46] M. Petrosino, A. Rubino, Synth. Met. 161 (2012) 2714.

[47] J.C. Bern $\square$ de, L. Cattin, M. Makha, V. Jeux, P. Leriche, J. Roncali, V. Froger, M. Morsli, M. Addou, Sol Energ Mater Sol C 110 (2013) 107.

\section{Note and references:}

Electronic Supplementary Information (ESI) available. See DOI:

\section{ToC image and text:}

Solution-processed copper(I) iodide $(\mathrm{CuI})$ is demonstrated to be an effective hole transporting layer (HTL) for several polymer:fullerene bulk heterojunction (BHJ) systems, leading to demonstration of efficiency up to $8.8 \%$ in the standard device configuration and in many cases surpassing the performance of devices
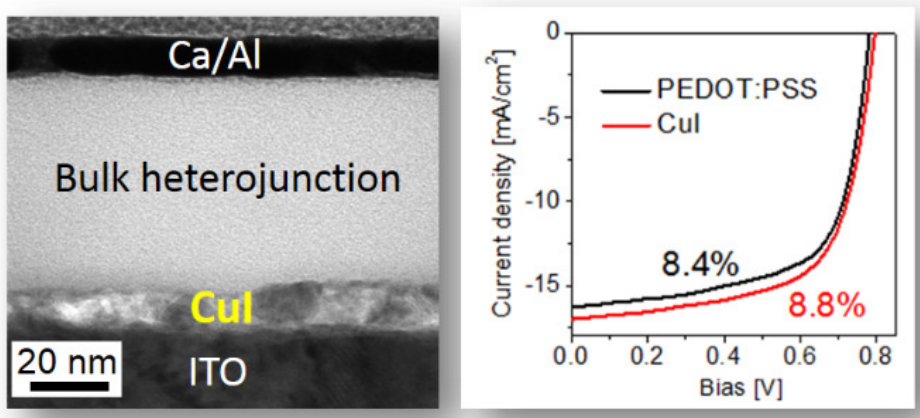
based on PEDOT:PSS as HTL. 


\section{Authors}

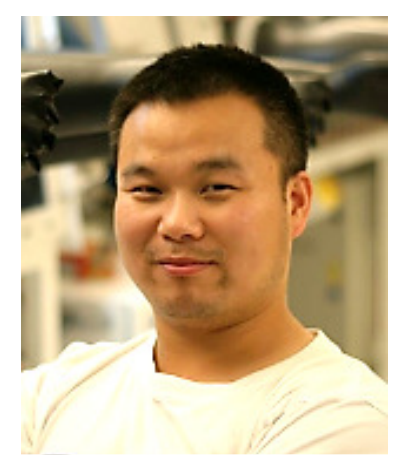

Kui Zhao received his Ph.D. degree in Materials Science Engineering from Chinese Academy of Science (CAS), China, in Jan 2010. He is currently working as a postdoctoral fellow in the group of Dr. Aram Amassian at the King Abdullah University of Science and Technology (KAUST), Saudi Arabia. His current research interests focus on renewable energy including perovskite solar cell, organic photovoltaics, quantum dots solar cell and organic electronics.

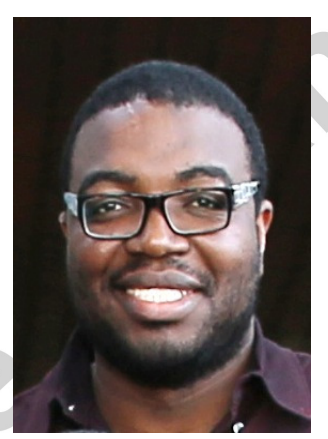

Guy Olivier Ngongang Ndjawa received his M.S degree from The African Institute for Mathematical Sciences, Cape Town South Africa in 2010. He is currently a PhD candidate under the supervision of Dr. Aram Amassian at King Abdullah University of Science and Technology (KAUST). His research focuses on the role of molecular packing in functional interfaces in organic solar cells.

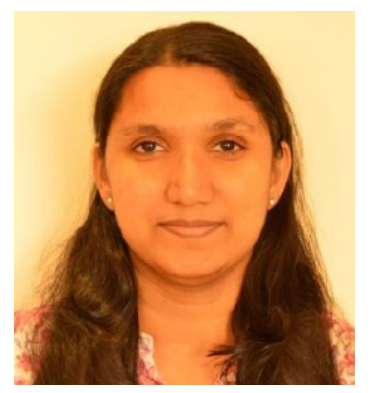

Lethy Krishnan Jagadamma is currently a postdoctoral fellow in the Amassian group at the Solar and Photovoltaics Engineering Research Center (SPERC) of King Abdullah University of 
Science and Technology (KAUST), Saudi Arabia. Her research interests are mainly solution processed and vacuum evaporated metal oxides for optoelectronic devices such as organic, quantum dot, perovskite solar cells, and light emitting diodes.

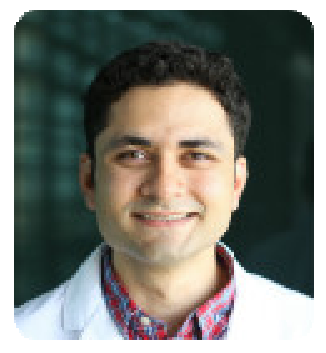

Abdulrahman El Labban is a Research Engineer at the Solar and Photovoltaics Engineering Research Center (SPERC) of King Abdullah University of Science and Technology (KAUST), Saudi Arabia, and was formerly a member of the research group of Prof. Pierre Beaujuge at KAUST. His research interests are mainly solution and vacuum processing, optimization and characterization of thin-film organic/inorganic electronic devices for energy conversion.

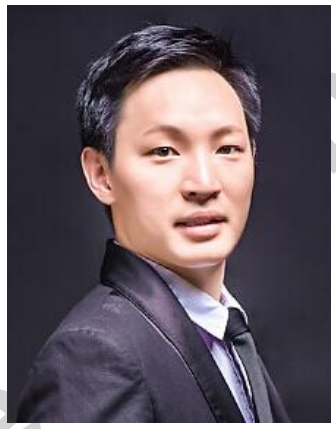

Hanlin Hu received the MS degree from Tianjin University of Science and Technology, Tianjin, China, in 2012. He is currently a Ph.D. candidate student with Dr. Aram Amassian at King Abdullah University of Science and Technology (KAUST). His research interests include organic thin film transistor fabrication and characterization, electron microscopy, organic solar cells.

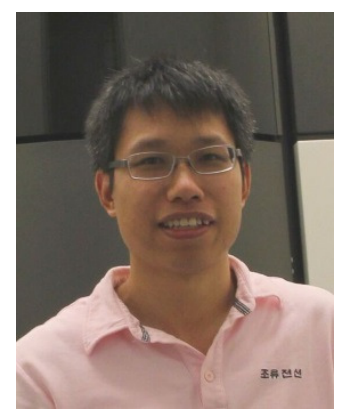

Qingxiao Wang is a research scientist in Advanced Nanofabrication Imaging and Characterization Laboratory of King Abdullah University of Science and Technology 
(KAUST). His research interests are mainly in the field of electron microscopy such as structural characterization of III-V semiconductors and in-situ study of 2D transition metal dichalcogenide (TMD) nanomaterials.

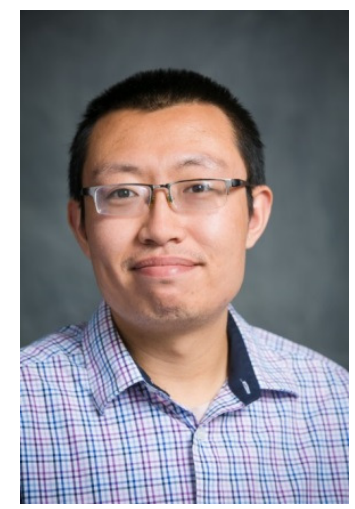

Ruipeng $\mathbf{L i}$ is a former member of the Amassian group who completed his postdoctoral fellowship at the King Abdullah University of Science and Technology (KAUST) after receiving his Ph.D. degree in National Synchrotron Radiation Laboratory, China. He is currently working at the Cornell High Energy Synchrotron Source (CHESS), Cornell University.

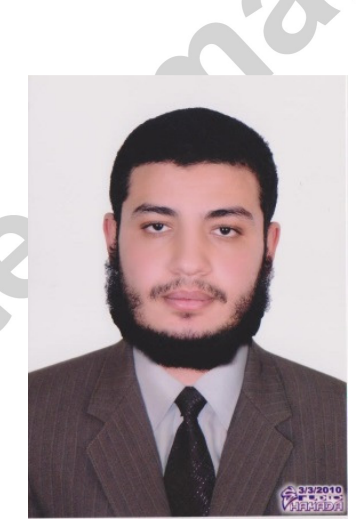

Maged Abdelsamie received master degree in Materials Science and Engineering from King Abdullah University of Science and Technology (KAUST), Saudi Arabia in 2012. He is currently Ph.D. student under supervision of Dr. Aram Amassian at King Abdullah University of Science and Technology (KAUST). His research interests include in situ characterization of thin film formation and device fabrication and characterization of organic solar cells, perovskite solar cells and organic thin film transistors. 


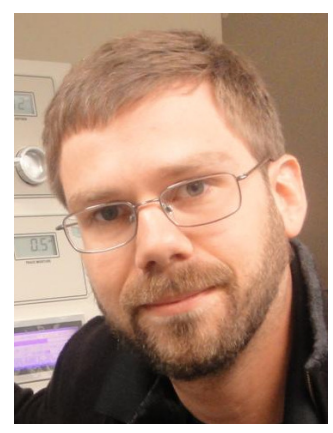

Pierre M. Beaujuge is Faculty in the Materials Sciences \& Engineering and in the Chemical Sciences Programs at King Abdullah University of Science \& Technology (KAUST). He is also a member of the Solar \& Photovoltaics Engineering Research Center (SPERC) at KAUST. He received his Ph.D. from University of Florida in 2009, and worked as a Post-Doctoral Associate at University of California, Berkeley (2009-2010) and in the Materials Sciences Division of Lawrence Berkeley National Laboratory (2010-2011).

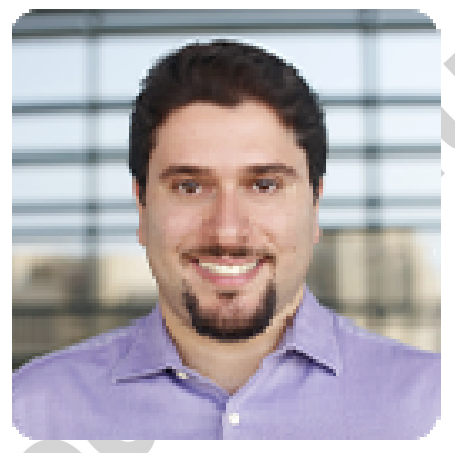

Aram Amassian is the Career Development SABIC Chair and Associate Professor of Materials Science and Engineering at the King Abdullah University of Science and Technology (KAUST). He is a founding member of the KAUST faculty as well as a member of the Solar and Photovoltaic Engineering Research Center (SPERC) at KAUST. He received his Ph.D. in Engineering Physics from Ecole Polytechnique de Montreal (Canada), and worked as a postdoctoral fellow in Materials Science and Engineering at Cornell University (USA). 
- Copper iodide (Cul) is demonstrated as an effective hole transporting layer (HTL) and replacement for PEDOT:PSS.

- Cul-based solar cells achieve higher open circuit voltage and yield highly efficient (>8\%) polymer:fullerene solar cells.

- Cul can be solution processed at room temperature and is shown to yield efficient solar cells on plastic substrates.

- Extremely robust and reliable in terms of processing temperature, solvent and thickness, yielding consistently good solar cells. 